\title{
The Influence of Fracture Healing under Different Working Length of Fixation System
}

\author{
Runxin Fang, Aimin Ji \\ College of Mechanical and Electrical Engineering, Hohai University, Changzhou, China \\ Frxin1994@163.com,jam@ustc.edu.cn
}

Keywords: working length, fracture healing, finite element analysis

\begin{abstract}
To explore the effects of working length on fracture healing, so as to provide the basis for related fracture treatment, the simulation of fracture healing under different working length were conducted using finite element method, and the change in the process of callus growth during healing periods was simulated based on the inter-fragmentary strain theory (IFS). The iterative process for updating callus modulus in every finite element was conducted by the second-developed ABAQUS based on Python code. Results show that the increased working length in a special range could have positive effects on the fracture healing, while exceeding the range would result in a negative effect, so it is a wise choice to choose a suitable working length for fracture healing process.
\end{abstract}

\section{Introduction}

Bone is the main component for bearing loads, fracture is commonly appeared in the high-energy accidents. Bone plate, one type of internal fixation, is an effective way to treat the fracture. Plate and screws can be integrated into a structure which can provide a stable mechanical environment for fracture healing. However, complications like failure of internal fixation, nonunion, delayed union and so on can occur in up to $10 \%$ of patients ${ }^{[1]}$. For this reason, a number of studies on internal fixation were conducted in the experimental or simulation way, with the experimental method, Field ${ }^{[2]}$ researched the influence of internal fixation stability under different screw configuration parameters, Tomkvist ${ }^{[3]}$ studied the relationship with internal fixation stiffness and the internal fixation parameters.

Nowadays, with the rapid development of computing technology, and the complex of the experiment in vivo, the finite element method is considered as an effective method to conduct research on the internal fixation system, Kim ${ }^{[4]}$ studied the stress distribution under different screw configurations using the finite element method, Lee ${ }^{[5]}$ conducted the research on the relationship between stability of internal fixation system and different screw configurations. The working length of bone plate, as one of the key factor in the fixation, has gathered a lot of focus from researchers ${ }^{[6-8]}$. Nevertheless, the studies above-mentioned to date have neglected the fact that bone is the living organ, so that this paper tries to study the influence of working length on the internal fixation based 
on the process of fracture healing using finite element method, which could provide an instruction for clinical usage in fracture treatment.

\section{Methods}

\subsection{Simulation of fracture healing}

According to the Perren's theory ${ }^{[9]}$, fractures can heal in the different rate based on the strain in the callus, so that the various strain in the callus is correspond to the different elastic modulus. Hyun-Jun Kim ${ }^{[10]}$ quantified the relationship between the strain and modulus, shown in Equation (1).

$$
E_{i}=\left\{\begin{array}{cc}
A e^{B x} & 0<x<2 \% \\
E_{\text {new }} & 2 \% \leq x \leq 10 \% \\
C e^{D(x-30)} & 10 \%<x<30 \% \\
E_{\text {gran }} & 30 \% \leq x
\end{array}\right.
$$

In Equation (1), $E_{\mathrm{i}}$ is modulus in the iteration $\mathrm{i}, x$ is the strain in the callus, $E_{\text {new }}$ is the renew modulus for each iteration, $E_{\text {gran }}$ is the modulus of granulation tissue, which is $0.05 \mathrm{MPa}$ in this study. The parameters of healing curve were shown in Table I.

TABLE I. Curve Parameters of Healing Rate Under Different Healing Period

\begin{tabular}{|c|c|c|c|c|c|}
\hline \multirow{3}{*}{$\begin{array}{c}\text { Healing } \\
\text { period } \\
\text { after fracture } \\
\text { /week }\end{array}$} & \multicolumn{4}{|c|}{ Strain/\% } & \multirow{3}{*}{$\begin{array}{c}\text { Elastic modulus } \\
\text { for new tissue } \\
E_{\text {new }} \\
/ \mathrm{MPa}\end{array}$} \\
\hline & \multicolumn{2}{|c|}{$0 \sim 2$} & \multicolumn{2}{|c|}{$10 \sim 30$} & \\
\hline & A & $B$ & C & $D$ & \\
\hline 4 & \multirow{4}{*}{0.02} & 1.1256 & \multirow{4}{*}{0.02} & -0.1126 & 0.19 \\
\hline 8 & & 3.6221 & & -0.3622 & 28.00 \\
\hline 12 & & 3.6665 & & -0.3667 & 30.60 \\
\hline 16 & & 4.1148 & & -0.4115 & 75.00 \\
\hline
\end{tabular}

In Figure 1, every discretized element of the callus was dealt with separately during the iterative calculation for the strain after the load was applied on the internal fixation system, the load was renewed and the modulus in the callus was updated with the usage of Python code at each end of iteration.

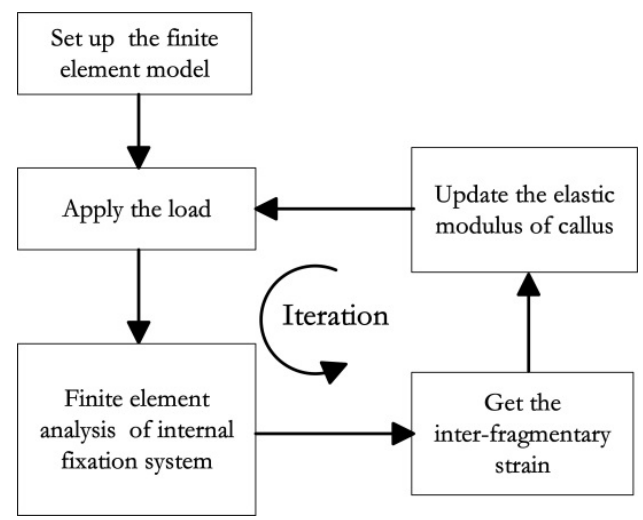

Fig. 1. The flow chart of iteration 


\subsection{Finite element model}

The bone was simplified into a cylinder composed of cortical and trabecular bones with a 3-mm transverse fracture, shown in Figure 2.

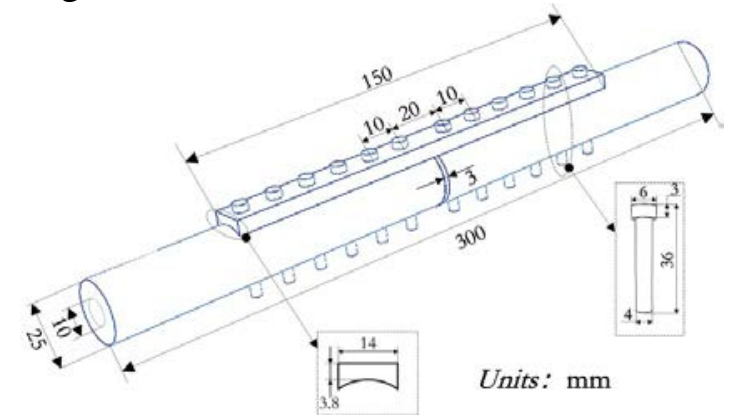

Fig. 2. Dimension of the internal fixation system

In the interaction condition, the interfaces between the screws and plate were tied, so were the interface of screw-cortical and screw-trabecular. In the loading condition, as shown in Figure 3, one side of the bones were fully constrained, and an axial load was applied on the other side of cortical surface.

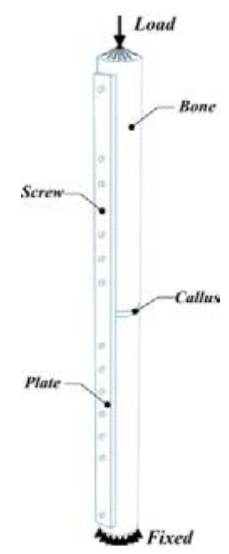

Fig. 3. Loading pattern of the internal fixation system

According to the Literature [11], the material properties of internal fixation was shown in Table II.

TABLE II. Mechanical properties of internal fixation system

\begin{tabular}{ccc}
\hline & $\begin{array}{c}\text { Elastic modulus } \\
(\mathrm{GPa})\end{array}$ & $\begin{array}{c}\text { Poisson's } \\
\text { ratio }\end{array}$ \\
\hline & $E_{\mathrm{x}}=18.4$ & $v_{\mathrm{xy}}=0.120$ \\
Cortical bone & $E_{\mathrm{y}}=7.00$ & $v_{\mathrm{yz}}=0.370$ \\
& $E_{\mathrm{z}}=8.50$ & $v_{\mathrm{xz}}=0.140$ \\
Trabecular bone & 1.100 & 0.3 \\
Plate & 105 & 0.34 \\
Screws & 105 & 0.34 \\
\hline
\end{tabular}

With the Literature [12] mentioned that patient lower limb fracture should exercise ankle joint in the first week, walk with crutches in the second week and gradually bearing load in the following weeks. In this study, the initial load after fracture was assumed to be $10 \%$ of the body weight and body weight is $70 \mathrm{Kg}$, the load magnitude under different healing time was shown in Table III. 
TABLE III. Relationship between axial load and healing period

\begin{tabular}{cc}
\hline $\begin{array}{c}\text { Healing period } \\
\text { after fracture } \\
\text { /week }\end{array}$ & $\begin{array}{c}\text { Axial load } \\
/ \mathrm{N}\end{array}$ \\
\hline 0 & 70 \\
4 & 350 \\
8 & 700 \\
12 & 1400 \\
16 & 2100 \\
\hline
\end{tabular}

From Rozbruch's research, 2 or 3 screws fixed in the main fragment can ensure the stability of internal fixation system ${ }^{[13]}$, so 6 screws were symmetrically used in the two main fragments in this study. In Figure 4, the screws were fixed symmetrically of the fracture plane, and the working length was changed with screws omitted in the different screw holes.

\begin{tabular}{|c|c|c|}
\hline $\begin{array}{l}\text { Numbering } \\
\text { of screw } \\
\text { fixation }\end{array}$ & \multicolumn{2}{|c|}{$\begin{array}{l}\text { Scheme of } \\
\text { screw fixation }\end{array}$} \\
\hline L126 & $\bullet \bigcirc \bigcirc \bigcirc \bullet \bullet$ & - • $\bigcirc \bigcirc \bigcirc \bullet$ \\
\hline L236 & - $\bigcirc \bigcirc \bullet \bullet \bigcirc$ & $\bigcirc \bullet \bullet \bigcirc \bigcirc \bullet$ \\
\hline L346 & $\boldsymbol{\bullet} \bigcirc \bullet \bullet \bigcirc \bigcirc$ & $\bigcirc \bigcirc \bullet \bullet \bigcirc \bullet$ \\
\hline L456 & $\bullet \bullet \circ \bigcirc 0$ & $\bigcirc \bigcirc \bigcirc \bullet$ \\
\hline
\end{tabular}

Fig. 4. Schemes of screw configuration under different working length

\section{Results}

The strain distributions in the callus under different healing period were shown in Figure 5.

In Figure 5, the strain distribution under healing period was varied with different working length, and so was the trend of change with fracture healing. Based on the fracture healing model, the optimal strain range of $2 \%-10 \%$ can guarantee the healing rate, and as shown in Equation (2), the healing rate $v_{\mathrm{i}}$ was defined as the ratio of elements in the optimal range.

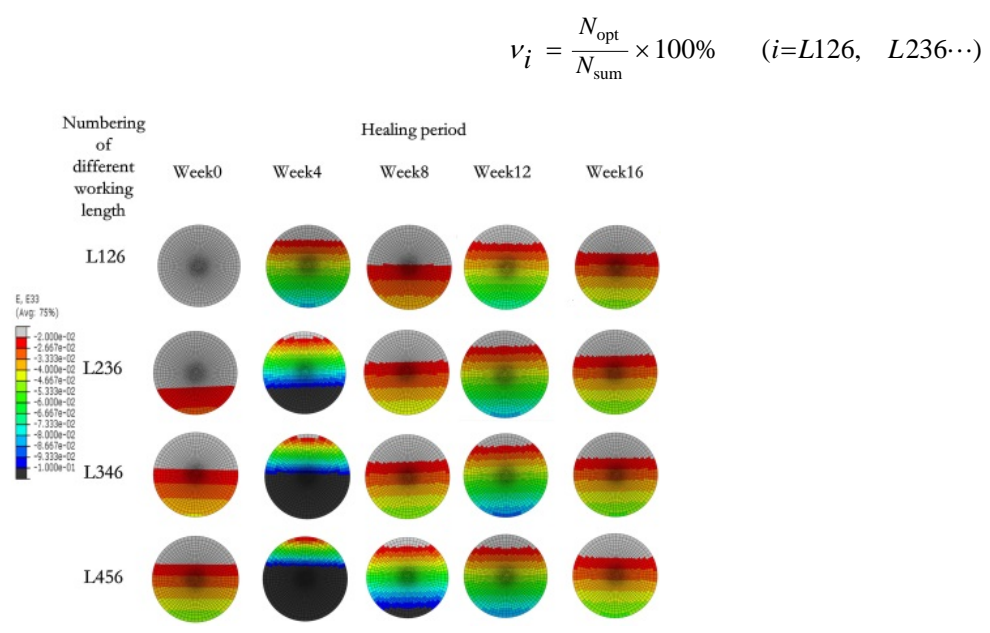

Fig. 5. Strain distribution under different healing period with various working length 
In Equation (2), $N_{\text {opt }}$ is the number of elements in the optimal range, $N_{\text {sum }}$ is the total number of elements in the callus. The healing condition (including healing rate $v_{\mathrm{i}}$, shown in Table IV (a); the maximum strain $\varepsilon_{\max }$ in the callus, shown in Table IV (b); and the healing results shown in Table $\operatorname{IV}(\mathrm{c}))$.

TABLE IV. The healing condition and result in the callus

(a) Healing rate under different healing period and various working length

\begin{tabular}{|c|c|c|c|c|c|}
\hline \multirow{2}{*}{$\begin{array}{c}\text { Numbering of } \\
\text { Working length }\end{array}$} & \multicolumn{5}{|c|}{ Healing period } \\
\cline { 2 - 6 } & Week 0 & Week 4 & Week 8 & Week 12 & Week 16 \\
\cline { 2 - 5 } & $v_{\mathrm{i}}$ & $v_{\mathrm{i}}$ & $v_{\mathrm{i}}$ & $v_{\mathrm{i}}$ & $v_{\mathrm{i}}$ \\
\hline L126 & 0 & 96.10 & 58.12 & 95.27 & 87.28 \\
\hline L236 & 12.99 & 87.72 & 81.34 & 96.84 & 89.51 \\
\hline L346 & 67.37 & 40.16 & 87.98 & 97.67 & 89.79 \\
\hline L456 & 88.07 & 14.45 & 96.82 & 97.30 & 90.74 \\
\hline
\end{tabular}

(b) Maximum strain in the callus under different healing period and various working length

\begin{tabular}{|c|c|c|c|c|c|}
\hline \multirow{2}{*}{$\begin{array}{c}\text { Numbering of } \\
\text { Working length }\end{array}$} & \multicolumn{5}{|c|}{ Healing period } \\
\cline { 2 - 6 } & Week 0 & Week 4 & Week 8 & Week 12 & Week 16 \\
\cline { 2 - 6 } & $\varepsilon_{\max }$ & $\varepsilon_{\max }$ & $\varepsilon_{\max }$ & $\varepsilon_{\max }$ & $\varepsilon_{\max }$ \\
\hline L126 & 1.62 & 8.06 & 3.82 & 7.28 & 5.09 \\
\hline L236 & 2.84 & 13.86 & 4.61 & 8.22 & 5.33 \\
\hline L346 & 4.07 & 19.40 & 5.24 & 8.88 & 5.38 \\
\hline L456 & 5.27 & 24.85 & 11.06 & 8.65 & 5.45 \\
\hline
\end{tabular}

(c) Healing results of various working length

\begin{tabular}{|c|c|}
\hline $\begin{array}{c}\text { Numbering of } \\
\text { Working length }\end{array}$ & $\begin{array}{l}\text { Healing } \\
\text { Results } \\
\text { (MPa) }\end{array}$ \\
\hline L126 & 65.7109 \\
\hline L236 & 68.0758 \\
\hline L346 & 69.6055 \\
\hline L456 & 69.2057 \\
\hline
\end{tabular}

\section{Discussion}

As shown in Table IV, the healing rate were varied under the different working length, and the working length has the greater influence on the healing rate than the later period, increasing the working length could sharply improve the healing rate after the treatment. However, the increased working length would reduce the healing rate to a lower magnitude in the healing period of week 4, further analysis revealed that the maximum strain was exceed the optimal range, which indicate that the callus was compressed excessively. The callus became harder as the healing period elapses, and the influence of working length was gradually reduced, while the rising trend was also appeared with the increased working length. However, the short working length could ensure the stability of internal fixation system, while the long one may do harm to the stability, which seems to be an optimal working length between the measurement of stability and healing rate. So it is necessary to take more consideration on the choice of working length. 
In this study, simplified cylinder was used for simulation of fracture healing under different working length, while for a more precise analysis, many aspects should be refined, a more thinning iteration step and realistic loading condition are essential for enhancing the accuracy of the simulation, for such information may have influence on the calculation of strain in the callus.

Finally, a quantitative relationship between the working length and the fracture healing, and the relationships between working length and different type of fractures are strongly needed for the further study, which is a prat of our future work.

\section{Acknowledgment}

This study was supported by the funds of "Postgraduate Research \& Practice Innovation Program of Jiangsu Province” (NO. KYCX17-0533) and "The Fundamental Research Funds for the Central Universities” (NO.2017b674X14).

\section{References}

[1] Gardner M J, Evans J M, Dunbar R P, "Failure of fracture plate fixation," Journal of the American Academy of Orthopaedic Surgeons, vol. 17, pp. 647-657, 2009.

[2] Field J R, Törnkvist H, Hearn T C, Smith S G, Woodside T D, "The influence of screw omission on construction stiffness and bone surface strain in the application of bone plates to cadaveric bone," Injury-international Journal of the Care of the Injured, vol. 30, pp. 591-598, 1999.

[3] Törnkvist H, Hearn T C, Schatzker J, "The strength of plate fixation in relation to the number and spacing of bone screws,” Journal of Orthopaedic Trauma, vol. 10, pp. 204-208, 1996.

[4] Kim J D, Kim N S, Hong C S, "Design optimization of a xenogeneic bone plate and screws using the Taguchi and finite element methods," International Journal of Precision Engineering \& Manufacturing, vol. 12, pp. 1119-1124, 2011. [5] Lee C H, Shih K S, Hsu C C, Cho T, "Simulation-based particle swarm optimization and mechanical validation of screw position and number for the fixation stability of a femoral locking compression plate," Medical Engineering \& Physics, vol. 36, pp. 57-64, 2014.

[6] Heyland M, Duda G N, Haas N P, Trepczynski A, Dobele S, "Semi-rigid screws provide an auxiliary option to plate working length to control interfragmentary movement in locking plate fixation at the distal femur," Injury-international Journal of the Care of the Injured, vol. 46, pp. S24-S32, 2015.

[7] Harvin W H, Oladeji L O, Della Rocca G J, Murtha Y M, Volgas D A, "Working length and proximal screw constructs in plate osteosynthesis of distal femur fractures," Injury-international Journal of the Care of the Injured, vol. 48, pp. 2597-2601, 2017.

[8] Hoffmeier K L, Hofmann G O, Mückley T, "Choosing a proper working length can improve the lifespan of locked plates. A biomechanical study,” Clinical Biomechanics, vol. 26, pp. 405-409, 2011.

[9] Perren S M. "Evolution of the internal fixation of long bone fractures. The scientific basis of biological internal fixation: choosing a new balance between stability and biology," Journal of Bone \& Joint Surgery British Volume, vol. 84, pp. 1093-1097, 2002.

[10] Kim H J, Kim S H, Chang S H, "Finite element analysis using interfragmentary strain theory for the fracture healing process to which composite bone plates are applied," Composite Structures, vol. 93, pp. 2953-2962, 2011.

[11] Mehboob H, Son D S, Chang S H, "Finite element analysis of tissue differentiation process of a tibia with various fracture configurations when a composite intramedullary rod was applied," Composites Science \& Technology, vol. 80, pp. 55-65, 2013.

[12] Zhang S K, Wang X H, Du M X, Chen J W, Zhao S H, Zhao G Q, "The Therapeutics of Fracture Biomechanics," Peking: China Science and Technology Press, 2001. pp. 81-82.

[13] Rozbruch S R, Müller U, Gautier E, Ganz R, "The evolution of femoral shaft plating technique," Clinical Orthopaedics \& Related Research, vol. 354, pp. 195-203, 1998. 